\title{
Deaf-blindness: Voices of mothers concerning leisure-time physical activity and coping with disability
}

\author{
Dana Štěrbová* and Martin Kudláček \\ Faculty of Physical Culture, Palacký University, Olomouc, Czech Republic
}

Copyright: (C) 2014 D. Štěrbová and M. Kudláček. This is an open access article licensed under the Creative Commons Attribution License (http://creativecommons.org/licenses/by/4.0/).

Background: Deaf-blindness (DB) is a distinct disability because of combined impairments of hearing and visual functions, causes severe difficulties in the psychosocial area, communication, social interaction, and interaction with the environment. Leisure-time physical activities (LTPA) properly planned and executed can be beneficial in providing support and facilitating coping as strategy for managing stress in families of children with disabilities. Appropriate LTPA also influence the quality of the lives of people with DB. Our study was also based on coping theory. Objective: The purpose of this study was to examine the beliefs of mothers with regard to leisure-time physical activity of families of children with deaf-blindness, the benefits that activities can bring to families of children with DB, needs and the barriers to participation. Methods: Participants of this study were five mothers of children with DB, who were interviewed using the phenomenological tradition of qualitative inquiry. Results: Findings show six emergent themes in relation to perceived needs of children with DB: structure of life; coactive engagement; happiness and well-being; doing "normal things"; appropriate support and services; and appropriate communication. Conclusion: The results of the present study indicated that there are various support systems, which could facilitate participation in LTPA: (a) special schools and respite care centers; (b) special programs such as family camps or programs where children can learn basic skills needed for participation in physical activities (e.g., swimming or biking); (c) adapted equipment which can allow participation; (d) parental support groups where parents can share common experiences or religious support groups, which might be able to accept a family with a child with DB as equal member of their community; and finally (e) assistance, which could have a formal form of professionals or paraprofessionals working with persons with DB. The absence of these support systems creates barriers to participation in LTPA due to the children's lack of skills, limited accessibility and non-existence of specialized year round programs.

Keywords: family stress, personal resources, family coherence, social support, deaf-blindness

\section{Introduction}

Individuals are regarded as deaf-blind if they have concurrent hearing and visual impairments causing difficulties in communication, access to information, and mobility (Simms, 2004). These difficulties generally result in high levels of stress for families, teachers and other caretakers (Štěrbová, 2005). Some people with deaf-blindness (DB) are totally blind and deaf while others have some functional use remaining in one or both senses. Some are born with DB (i.e., congenital DB) while others acquire this impairment through disease. Deaf-blindness is a distinct disability, which is caused by the combination of hearing and visual impairment.

\footnotetext{
* Address for correspondence: Dana Štěrbová, Department of Social Sciences in Kinanthropology, Faculty of Physical Culture, Palacký University, tř. Míru 115, 77111 Olomouc, Czech Republic. E-mail: dana.sterbova@upol.cz
}

This disability, due to combined impairments of hearing and visual functions, causes severe difficulties in the psychosocial area, communication, social interaction, interaction with the environment, and in meeting the needs of persons who are deaf-blind. At the same time this disability hinders full inclusion in everyday life in society (Štěrbová, 2005).

Leisure-time physical activities for individuals with DB Leisure is defined by two criteria: (a) is entered voluntarily and of free choice and (b) is intrinsically motivating in and of its own merit (Priest, 1999). Carter, Van Andel, and Robb (2003) highlight the importance of leisure-time experiences as one of the major goals of therapeutic recreation with the potential to significantly contribute to quality of life. Therapists within leisure education typically facilitate: (a) sense of freedom; (b) satisfaction; and (c) joy. One way of coping with 
stress is to help professionals and families to plan and execute relevant leisure-time physical activity (LTPA) that allow some choice making by children with DB. Research on family recreation and leisure-time physical activity is still in its infancy, but can potentially lead to enhancement of life by explaining psychosocial benefits of leisure-time activities to families of persons with disabilities and by helping them to understand the barriers that affect family LTPA (Scholl, McAvoy, Rynders, \& Smith, 2003).

Leisure-time physical activities properly planned and executed can be beneficial in providing support and facilitating coping as strategy for managing stress in families of children with disabilities (Castaneda \& Sherrill, 1999; Weiss, 2008). Appropriate LTPA also influence the quality of lives of persons with DB (Lieberman \& Stuart, 2002). Reasons for participation in LTPA vary. For persons with disabilities these reasons might include fun, exercise, meeting others, entertainment, challenge, occupying the mind, or a change of environment (Smith, 1994). Thus LTPA can fulfill a great variety of needs for persons who are deaf-blind. LTPA facilitates communication among individuals with DB (Lieberman \& Stuart, 2002), and it can facilitate transition from school to vocational life (Huven \& Siegel, 1995; Lieberman \& Stuart, 2002). It may help in promoting inclusion in community life and can foster friendship and other relationship opportunities (Lieberman \& Stuart, 2002; Ray, 1991). LTPA can also provide opportunities for participation in fitness-related activities (Lieberman, 1999; Lieberman $\&$ Stuart, 2002).

Current involvement of individuals with DB in LTPA, their preferences, barriers to participation and possible solutions to these barriers are discussed by Lieberman and Stuart (2002). There are numerous activities that persons with DB can take part in, but they must have choices and know how to access them. Persons with DB experience a great amount of social isolation (McInnes, 1999; Petroff, 1999), which can make their LTPA participation more difficult. Additionally Lieberman and Stuart (2002) reported the following barriers: transportation, lack of others to participate with, lack of adequate programs, lack of time, negative attitudes of those offering the activity, and lack of communication. The present study is an elaboration of research by its focus on the perspectives of mothers of children with DB, related to engagement in LPTA in their families.

\section{Coping theory}

Families of children with DB are often under a tremendous amount of stress (Štěrbová, 2005, 2013). Concepts of family stress and family crisis are presented frequently in both clinical and research literature (Satirová, 1998; Sobotková, 2001; Vágnerová, 2009; Štěrbová, 2013). Family crisis can then be defined as incapability or disorganization of family, where there are no more resources available to control stress (Hill, 1949). Four factors influence family adjustment to stressors: (a) personal resources of the family members; (b) inner sources within the family system; (c) social support; and (d) coping. Coping consists of both cognitive and behavioral efforts that are used to control stressful transactions and thus is an integral feature of emotion (Lazarus, 2006). Coping helps the individual to face the problem itself as well as to handle unpleasant emotions that appear as a consequence of the problem. Due to the fact that a family is a system, coping behavior involves the management of various family life dimensions, simultaneously. These are (a) maintaining satisfactory conditions supporting family communication and organization; (b) supporting the independence and dignity of each family member; (c) maintaining family coherence and unity; (d) maintaining relations or developing social support with community; and (e) retaining certain level of the effort to control stress and changes within the family unit.

Coping thus becomes a process that facilitates the achievement or maintenance of the stability and unity of the family system and it supports individual growth and development. The general coping style of a family depends on various factors such as the circumstances, the extent to which the threat becomes incorporated into family relations and tasks, available family resources, and previous experience of the family. Families of children with DB can serve as great support and the earliest teachers of their children. On the other hand, families need support as having child with DB brings on tremendous challenges. A very effective kind of support can be provided by reference groups of parents of children with disabilities in informal or formal meetings such as family camps (Seligman \& Darling, 2007; Štěrbová, 2013), family support organizations, and grandparents or extended-family members (Jackson, 2011; Jackson, Traub, \& Turnbull, 2008; Štěrbová, 2013).

Motor skills are considered to be prerequisite to the development of any form of formal communication (Jackson, Traub, \& Turnbull, 2008) and participation in physical activities can increase the likelihood of independence and improve the quality of life of children with DB (Lieberman \& Taule, 1998). At the same time leisure time physical activity can be practiced by the whole family and can also serve as an effective coping mechanism (Štěrbová, 2002). So far no research 
has been conducted about the current state of LTPA for persons who are deaf-blind in the Czech Republic.

The purpose of this study was to examine the beliefs of mothers with regard to the LTPA of families of children with $\mathrm{DB}$, the benefits that activities can bring to families of children with DB, needs and the barriers to participation.

\section{Methods}

\section{Participants}

A purposive sampling design was used (Thomas \& Nelson, 1996). Participants of this study were five mothers (representing families) of children with DB. Mothers included in the study satisfied the following inclusion criteria: (a) their child's DB was congenital, (b) their child was between 15 and 21 years of age, and (c) their child was currently in a period of transition from school to home communities. In addition, each participant's family expressed willingness to take part. In the present study we define family in agreement with Kramer (1980) as a group of people who have common history, present reality, and future expectations of mutually interwoven transactional relations. In our sample four of five families did not include a father. Pseudonyms are used to refer to the children with DB, to protect their identity.

Participant 1: Mother of Eva. Eva is a 16 year old female who has complete blindness (congenital) and was subsequently diagnosed with a severe hearing impairment. Eva's family includes her mother (41 years old), father (40 years old), and a brother who is two years older than Eva. Eva remained at home until she was 6 years of age, at which point she was enrolled in a special experimental boarding school for children with DB in the Czech Republic. The first year she followed the preparatory curriculum which was designed specially for students who are DB. Currently the curriculum is being modified. Eva is very friendly to those who can communicate with her and has a high cognitive level. The family lives in a rural area and is supportive. Eva lives in a boarding school, but comes home on weekends. She communicates with signs using her hands and body. Eva moves independently without assistive devices but requires a personal assistant for successful participation in LTPA.

Participant 2: Mother of Martin. Martin is a 19 year old male with partial blindness, a severe hearing impairment, and a severe intellectual impairment. His family includes only Martin and his mother (who is 41 years of age). Martin lives at a specialized experimental boarding school for children with DB during the week but usually goes home to live with his mother on weekends.
However, when his mother has had to work over the weekend, he has remained at the boarding school; Martin's mother must work to support them both. Prior to being enrolled in the specialized boarding school he attended eight different institutions. Martin's progress at the specialized school has been slow due to his low cognitive ability. He communicates with a limited number of signs and needs an assistant at all times. Martin's mobility is progressively getting worse and he uses a walker or wheelchair for long distances.

Participant 3: Mother of Paula. Paula is a 21 year old female. Her congenital impairments include complete blindness, a severe hearing impairment, a mild intellectual impairment, and epilepsy, as a result of her mother contracting rubella while she was pregnant. Paula's family includes her 41 year old mother and herself. Prior to age 8 when she began attending the specialized boarding school, Paula lived at home with her mother, who was on a prolonged maternity leave. During that time, Paula unsuccessfully attended several different institutions. She has now completed her education at the specialized school and her family is currently trying to find a new instituation to meet her needs. She lives with her mother and grandmother in a rural community. Paula uses sign language to communicate, with approximately 20 signs in her repertoire. She engages in ritualistic behaviors and has difficulty adjusting to new environments. She is able to take care of herself when at home, but needs a personal assistant outside of the home.

Participant 4: Mother of Zora. Zora is a 19 year old female who has DB and a severe intellectual disability. Zora and her mother (41 years of age) live in a rural area with her and two sisters (aged 17 and 20 years). She enjoys helping with household chores. Zora attends a special school for students with DB and communicates with signs. She actively uses four signs but can understand more. She is able to move independently and without any assistance devices, but requires a personal assistant for successful participation in LTPA.

Participant 5: Mother of Patrick. Patrick is a 17 year old male who lives with his mother (41 years of age) and older brother (18 years of age). He has DB and a moderate intellectual disability. Patrick and his family live in a small town and, since age five, has attended a special experimental school for DB near home. He had significant problems with spatial awareness and fear, which impacted his ability to perform gross motor skills. He is fixated on his mother and exhibits autistic behaviors (collecting car models and catalogues).

\section{Procedures}

Ethics approval for this study was obtained from Ethical Committee of the faculty at the University 
of Principal Investigator and all participants signed informed consent. Given the role of principal investigator in counseling these families, study participants were also informed of her role as a researcher on the study. Counseling was professionally supervised and research aspects of direct involvement of PA are discussed in section on verification.

\section{Interview guide and pilot study}

We developed and validated the interview guide to obtain basic information about the LTPA of the five families. The interview guide was validated and approved by a panel of three independent experts: (a) a university professor with a specialization in adapted physical education (APE) or special education; (b) a special education teacher with experience with children with DB; or (c) a psychologist (counselor) with experience with children with DB. The pilot study was conducted with two families with children with DB. In the current study the following questions were used: (a) How important are leisure time physical activities in your family?; (b) Is your family taking part in organized leisure time physical activities?; (c) Which activities can be done with your child who has DB?, (d) Are options of leisure time physical activities sufficient?

\section{Interviews with mothers}

Interviews with mothers of children with DB were conducted to collect data on the lives of participating families. The presented paper is part of larger study focusing on family stress and coping behaviors in families with children with DB (Štěrbová, 2002). Participants have signed informed consent forms. The primary investigator conducted full interviews. We have prepared semistructured interviews based on previous studies of families of children with hearing impairments (Sobotková, 2003; Štěrbová, 2002). The length of the interview was approximately $120-180 \mathrm{~min}$. Interviews took place in the homes of the families. In one case where a father was part of the family, he was present during the interview. Mothers knew the principal investigator from previous participation in programs for families of children with DB (family camps), where she provided service as a counselor (psychologist) and personal assistant. From the whole interview 4 questions (with subsequent follow up questions) were focused exclusively on leisure-time physical activities. The purpose of this study was to examine the beliefs of mothers with regard to the LTPA of families of children with DB, the benefits that activities can bring to families of children with DB, needs and the barriers to participation.

\section{Data analysis}

We have followed the phenomenological tradition of inquiry (Creswell, 1998). Data analysis was directed toward identification of emergent themes, which occur concurrently with data collection when using a naturalistic paradigm (Erlandson, Harris, Skipper, \& Allen, 1993). We followed the recommendation of Creswell (1998) that the researchers should engage in data analysis in a spiral fashion starting with data collection, managing the data, reflection with domain analysis (Spradley, 1980) such as memoing, comparing, describing, and interpreting. Interviews were audio taped, transcribed and sent to participants to check for accuracy. Data analysis was done by two researchers, who read the text, made marginal notes and formed initial codes. We followed with deductive analysis and interpretation of the meaning of the codes and confronted the codes with findings of similar studies (An \& Goodwin, 2007; Scholl, McAvoy, Rynders, \& Smith, 2003). Finally we developed a structural description of mothers experiencing the phenomenon of participation in LTPA, which was similar to that used in related literature (Sobotková, 2003; Štěrbová, 2002; Štěrbová 2013; Vágnerová, 2009; Weiss, 2008).

\section{Verification}

We used the model of verification described by Creswell (1998), who refers to verification as a "set of techniques for obtaining and defining trustworthy data" (p. 198). Following are the procedures which we adopted for this study to assure trustworthiness. The principal investigator had been engaged long term with participants (families of children with DB) via counseling services and cooperation in family camps. This long engagement helped to build trust, to learn the culture of families with DB, and to check for misinformation (Creswell, 1998). Participants were also invited to check their own interview transcript and the interpretation of results. This engagement was for over a 1 year period. We also used triangulation of data as the principal investigator kept journal entries and field notes from interviews and also from participant observation in family camps. Additionally the principal investigator asked two colleagues, previously involved as experts for the interview guide, to provide a peer review of the whole research project. This step of verification was done in accordance with the recommendation of Dukes (1984), who asks for an outside objective reader to recognize the logic of the explored phenomenon (experiences of mothers of children with DB). 


\section{Results}

The purpose of this study was to examine the beliefs of mothers with regard to the LTPA of families of children with $\mathrm{DB}$, the benefits that activities can bring to families of children with $\mathrm{DB}$, needs and the barriers to participation.

None of the families participated in any specific leisure time program of adapted physical activities. Data are presented according to statements of participants and based on their experiences. Parents were not offered any choices of specific adapted physical activity intervention; the intent of the study was to map the current state of families. Physical activities of family members were studied separately in relation to all members and at the same time we also kept the focus on the whole family as functioning system. In all families we were surprised about barriers to participation. Mothers were often unable to identify exactly the specific barriers and limited their comments to the "disability of their child being the barrier". This is one of the examples of their lack of information as adapted physical activities for children with DB are almost nonexistent in Czech Republic. From the analysis of interviews with mothers there emerged the following themes. Children have a number of needs, some of them are general needs and some are specific for children with DB. The failure to meet the specific needs of children with DB can serve as family stressors. At the same time, when needs of children with DB and their families are met (barriers are overcome), participation in LTPA can serve as effective coping. In this section we first introduce emergent themes which describe interrelated phenomena of LTPA, stress and coping in families of children with DB. Then we apply emerged themes in order to describe and analyze the situation in families in relation to LTPA. In providing direct quotes we have used translation from Czech to English.

\section{Emergent themes: Needs of children with DB and their families}

Emergent theme one: Structure to life

Mothers reported the constant challenge of providing structure to their child's life and increase awareness of activities associated with the passage of time from day to night. Mothers believed that physical activities (PA) and leisure-time activities (LTA) can facilitate a structure into the daily (weekly) schedule very much needed for children (with limited visual and audio stimuli) who have a difficult time distinguishing between day and night.

...for example we go swimming twice a week. We do this for our child...it is the regularity, which we try to follow for her...
...So I must create some program for him, as he likes to do things, I for example, would screw something and he would unscrew it (e.g. cap from plastic bottle or wooden toys). Any we do this maybe 3 hours. (Note. Her son has this activity connected with the travel from/to school.)

\section{Emergent theme two: Coactive engagement}

Mothers perceive the constant need to prompt their child into physical activity as well as the need for coactive engagement with their child in LTPA. Children have the need to take part in activities and, if activities are not provided to them or their participation is not facilitated they may take part in activities that are not desirable.

...She is sitting and is seeking something to do...so for example she throws out the trashcan, or she finds something to do. For example she has found string (belt) in pans she can pull out and play with...

...He needs to be entertained, somehow fill up leisure time. I must create some program for him, entertain him, and teach him. He can play a little by himself, but only for short time...

\section{Emergent theme three: Happiness and well-being}

Mother frequently noted the wish and hopes to provide activities that would enable their child to demonstrate happiness. Mothers indicated that they needed to feel that their children are achieving something. Parents believed that participation in PA or LTA and successful completion of some tasks can bring children happiness and joy.

...she is happy when we say we will go on a trip, she gets excited and that is good to see...

...When we go by train, he loves it, on the train he likes to communicate using sign language, which he did not want to do before. Yep so it is so laid back... ...She likes to butter a baking plate with a brush, so I let her do it...or even cut things. I know she is careful... ...She loves walking and exercising in nature, which she expresses with loud laughter. After completing some task or overcoming a challenge, she is happy for the achievement and is looking forward to our praise...

...I have seen videos from family camps and I was surprised what all we can expect children with $D B$ to achieve...

For parents it is important that their children are healthy and fit. This need can serve as great source of motivation to take part in physical activities.

...We go swimming, so we would not get so fat. She has the tendency to gain weight, so we try to do exercise... 
...This bicycle, I have modified so if I push him his pedals will move...so I am pushing and he is not pedaling, but still it moves his legs, yeah...

\section{Emergent theme four: Doing "normal" things}

Mothers reported their desire for their children to do "normal" things. Parts of leisure-time activities are the everyday activities such as cleaning, gardening, cooking or physical activities. Mothers reported they realized sense of satisfaction as their child could do something that is associated with normal behavior.

...she likes to prepare meals. For example when I am cooking I take her to the kitchen. She loves to help when I am baking, like she is greasing the baking tin. Or cutting something...yes with knife I know she is careful...

...now he understands that clothing has some purpose, and he is dressing by himself. He knows how to dress by himself, well most of the stuff he can put on by himself...

...great experience was at summer holiday, when she overcame the fear of getting in the swimming pool without assistance, so she would not just lay on the bench...

...family camps in Slovakia, Italy or Denmark. It was great to go swimming, trampoline activities, hand painting, theatre plays, arts and crafts, like painting on silk... Great feelings...

Emergent theme five: Appropriate support and resources Mothers reported a need to take time off their parental duties as they live "with the rhythm of child" and can be exhausted and later burned out. They need support programs that can facilitate their coping with being parent of child with DB. Adapted physical activity organized programs can serve as great support service to families. ... We all used to do tandem biking, but now my legs are worn out. We would go swimming but not so much as one is exhausted from "all of that" so I just manage to do shopping... It is all more demanding...

...If she could go some place where somebody would provide services, take care of her, work with her... I would need somebody who would help me, maybe in the mornings take care of her and then I could go to work based on our needs...

...What would help? Assistance from other people, maybe friends... I am not twenty anymore. My legs and arms are worn out, often I drop things from my hands...

...I have spoken with her personal assistant about the possibility to visit a thermal spa. So she could do this activity also without us...
Emergent theme six: Appropriate communication

Mothers reported that finding the best method to communicate was significant challenge. Mothers claimed that the assistants must be prepared not only in the area of adapted physical activities, but also in the area of communication as this is the basic prerequisite to any programming. Every child with DB has a unique method of communication, which is generally best known by their parents.

...you must find the right way how to tell him... for example you think this is the way I should teach him, it is simple he will understand, but he might not understand...so I must find a way to explain to him... ...So, for example, when he takes my hand and pulls it towards him, I know that he wants me to scratch his back, so I scratch his back...

...I have found out that she reacts later...(has latent reactions)...well maybe 25 seconds or so...

...We walk the dog to the big tree - which is our sign (mother signs "big tree"). Then we walk to visit the columns...

\section{Situation in families}

The ethnic composition of families was homogeneous (Caucasian) with all families speaking Czech as their first language and following traditional Czech customs. All children with DB stayed at boarding school during the week and with family over the weekend. All children needed a personal assistant and all (except Martin) had independent mobility.

Family 1 (Eva)

Mother and father are trying to participate in a LTPA with both children. During holidays and weekends they engage in same activities. The older son (brother of Eva) does not take part in walking activities as he prefers his personal hobbies (car maintenance - his vocational training). He takes part in activities in family camp programs. During the week, while daughter (DB) is at boarding school, the parents regularly play squash (common bonding activity). Mother in her LTPA (aerobics, oriental dance) uses her time to relax from her daily duties. Father spends his free time in house maintenance. Daughter with DB (Eva) usually takes part in adapted physical activities (tandem biking, sauna) at boarding school. These activities cannot be provided by parents as mother is not strong enough for tandem biking and sauna is not available close to their home. That is the reason why most common activities are solely based on walking activities. The family would appreciate a wider range of organized activities. During summer holidays, the family enjoys spending time on the water. Although Eva cannot swim, she enjoys spending time in shallow water, which 
needs to have pleasant temperature. The family considers LTPA to be important for healthy lifestyle and also to help to "tire out" Eva so she can sleep more calmly. During the interview the mother reported that she would appreciate if APA service would be provided by state or non-governmental organizations, but currently there are no such organizations. We could describe the family as open and active in seeking LTPA, which help them to cope with family stress. Both parents are fully employed to maintain desired family living standards.

\section{Family 2 (Martin)}

This family has two members - mother and son (19 year old). The mother has overcome many challenges related to Martin's numerous moves from one institution to another. She seems to be strengthened by these challenges. Her personality is also reflected in LTPA as she is actively including Martin in these activities and facilitates conditions for his success. Among his most favorite activities are bowling and traveling by train, which is the transportation mode to school. Organized physical activities take place at the boarding school and mainly include APE, swimming, and biking. Due to the severity of impairment, there is a great need for safety and support, thus bringing forward the need for an assistant. The mother perceives all LTPA as activities supplementary to physiotherapy, which is needed by Martin. Physiotherapy is not provided at school and cannot be provided over the weekends due to practical and financial reasons. LTPA provide them the opportunity for social interaction with their interest group. The greatest barrier the mother perceives is the lack of opportunities for children with DB because of inadequate information and organized LTPA.

\section{Family 3 (Paula)}

This family has two members - mother and daughter (21 year). Mother focuses primarily on meeting the needs of Paula. The need of regular schedule for Paula is so important that an external viewer might perceive that all activities (LTPA) of family members are determined by the LTPA forms, which can be practiced by Paula. The mother claims that these activities are important for her and her daughter for health, fitness and appearance. Due to the need for a regular schedule, all LTPA are recorded on the calendar (pictures and symbols). Paula is asked to do her daily exercise (stationary bike) at exact time daily. This regularity is sometimes burdening for the mother. Daily activities such as shopping are often family trips. The mother reported gardening (garden relaxation) as the most important LTPA. Mother claims that participation in LTPA could be facilitated by more leisure time and more assistive service. This also could be interpreted that, with more assistance, Paula could devote more time to her LTPA.

\section{Family 4 (Zora)}

This family is comprised of a mother and three teenage daughters. Their family life is closely connected to religious services, where they find satisfaction. Zora is included in all LTPA (e.g., swimming, cycling). These activities cannot be done regularly due to the financial situation of family. The family also likes trips and walks, and all members take turns using their home stationary bicycle. They also attend regular organized exercises, which are perceived by the mother as physical and psychological satisfaction. They participate in this LTPA without Zora (she stays home with one member of family). Zora likes to swim (exercise in water) with her family at summer holiday family camps. Zora's mother considers sleeping to be part of her daughters' LTPA as she likes this activity. Zora is included by her mother and sisters in house chores (e.g., ironing, wood chopping). Her most favorite activity is drawing and painting.

\section{Family 5 (Patrick)}

The family is comprised of mother and two teenage sons. During the interview the mother focused solely on Patrick. Because of his autistic-like behaviors, she tries to fill his leisure time with meaningful activities. Patrick has his own TV set and particularly enjoys watching automobile races. He likes to look through car magazines and also enjoys walking. Patrick does not take part in LTPA of his mother and brother. The mother likes to do exercise (typical for Czech females), which brings her joy and relaxation. Patrick attends special school and also participates in APE lessons (e.g. swimming, bicycle, and skiing). Family likes walking or biking. The mother would like to have regular assistance with LTPA.

\section{Discussion}

Deaf-blindness is a relatively new area of interest in Europe, including the Czech Republic. In the Czech Republic the rights of people with DB are represented by multiple nongovernmental organizations. An influential organization which also took part in our study is named "Zablesk" (English translation = flash). Deafblindness is slowly being recognized by Czech professionals as a distinct disability, but a lack of services for families of children with DB remains especially in the areas of education and leisure time physical activity.

Our findings show that we need to focus our attention not only to persons with $\mathrm{DB}$, but to mothers of 
children with DB and whole families (a holistic system with interconnected subsystems). If we look at the family from this point of view we see that the family of a child with DB must cope with a significant amount of stress (Štěrbová, 2005; Štěrbová, 2013). Success of this coping is dependent of previous experiences, the individual, as well as family coping mechanisms (Hill, 1949; Plaňava, 2000). Families of children with DB must cope with the multiple stressing factors. They must successfully cope with transitional crises (Sobotková, 2001), which are an ordinary part of family lives but also cope with non-normative events (Baltes, 1986).

The appropriate leisure time physical activities can help to reduce personal and family stress and facilitate appropriate coping. Currently there are more opportunities for children with visual impairments (Janečka, Kudláček, \& Válková, 2003) and only few opportunities for children with DB in the Czech Republic. LTPA can serve as a factor supporting communication and organization within each family. In LTPA every member of the family is participating as him (her) self. Therefore he (she) can reach certain aims and feel independent and still be a part of family activity. These mechanisms can support family coherence and unity (Sobotková, 2001). During LTPA in a natural environment (e.g. bowling, sledging) the family is in contact with community and can therefore use social support. When the family of a child with DB can engage in LTPA its members perceive themselves as "normal", which in turn might help them to cope with stress (An \& Goodwin, 2007; Jackson, Traub, \& Turnbull, 2008; Štěrbová, 2013).

Parents told us about their feelings of fulfillment of their child's needs. A significant finding is also that parents have similar needs and reasons for participation in LTPA, which we consider to be an important coping mechanism, a form of individual coping. Our study shows lack of support in organized (apart from school) LTPA and therefore the ways of using leisure time is solely on families of children with DB. When we consider parental satisfaction from mastery and participation of children, it is a concern that support services helping families to cope with DB are currently missing. At the same time we must admit that the lack of preparedness of conditions including basic information, information about specific needs in communication, information about special APA needs etc., can create barriers and in turn new stressors.

Therefore, if we want to offer appropriate LTPA we must keep in mind to assure conditions specific for: (a) the general need of persons with DB; (b) specific needs of a given individual based on his(her) skills and abilities; and (c) specific needs and requirements of a given family. We agree with Lieberman and Stuart (2002) who stated that there are numerous activities that persons with DB could take part in, but they must have choices and know how to access them. Professionals delivering these services need to have (a) appropriate training including knowledge and skills related to LTPA of persons with visual impairments; (b) appropriate communication skills; (c) practical experiences in work with children with DB or at least visual impairment and/or hearing impairment (Columna et al., 2008; Štěrbová, 2005).

\section{Conclusion}

From the accounts of interviewed mothers it is evident that they perceive multiple benefits from their children's participation in LTPA. Mothers also expressed that there is a need for support systems which would help parents in coping with the identity of a parent having a child with DB as well as with the functioning of the family system in way that the family can fulfill the needs of all its members. There are various support systems, which could facilitate participation in LTPA: (a) special schools and respite care centers; (b) special programs such as family camps or programs where children can learn basic skills needed for participation in PA (e.g., swimming or biking); (c) adapted equipment which can allow participation; (d) parental support groups where parents can share common experiences or religious support groups, which might be able to accept a family with a child with DB as equal member of their community; and finally (e) assistance, which can have formal form of professionals or paraprofessionals working with persons with DB (Seligman \& Darling, 2007). Relatives and friends may also help parents to take some time off. The absence of these support systems creates barriers to participation in LTPA due to the lack of the skills of children, limited accessibility and non-existence of specialized year round programs. At this moment the only specialized program for families of children with DB are family camps organized by parental group Zablesk (transl. $=$ flash).

\section{References}

An, J., \& Goodwin, D. L. (2007). Physical education for students with spina bifida: Mothers' perspectives. Adapted Physical Activity Quarterly, 24, 38-58.

Baltes, P. B. (1986). Theoretical propositions of life-span developmental psychology. Berlin: Institute for Human Development and Education. 
Carter, M. J., Van Andel, G. E., \& Robb, G. M. (2003). Therapeutic recreation: A practical approach (3rd ed.). Prospect Heights, IL: Waveland Press.

Castaneda, L., \& Sherrill, C. (1999). Family participation in challenger baseball: Critical theory perspectives. Adapted Physical Activity Quarterly, 16, 372-388.

Columna, L., Pyfer, J., Senne, T., Velez, L., Bridenthrall, N., \& Canabal, M. Y. (2008). Parental expectations of adapted physical educators. Adapted Physical Activity Quarterly, 25, 228-246.

Creswell, J. W. (1998). Qualitative inquiry and research design: Choosing among five traditions. Thousand Oaks, CA: SAGE.

Dukes, S. (1984). Phenomenological methodology in the human sciences. Journal of Religion and Health, 23, 197-203.

Erlandson, D. A., Harris, E. L., Skipper, B. L., \& Allen, S. D. (1993). Doing naturalistic inquiry: A guide and methods. Newbury Park, CA: SAGE.

Hill, R. (1949). Families under stress: Adjustment to the crises of war separation and reunion. New York, NY: Harper.

Huven, R., \& Siegel, S. (1995) Joining the community. In N. G. Haring \& L. T. Romer (Eds.), Welcoming students who are deaf-blind into typical classrooms (pp. 17-35). Baltimore, MD: Paul H. Brookes.

Jackson, C. W. (2011). Family supports and resources for parents of children who are deaf or hard of hearing. American Annals of the Deaf, 156, 343-362.

Jackson, C. W., Traub, W., \& Turnbull, A. P. (2008). Parents' experiences with childhood deafness: Implications for family-centered services. Communication Disorders Quarterly, 29, 82-98.

Janečka, Z., Kudláček, M., \& Válková, H. (2003). Sport socialization of children with visual impairments. Acta Universitatis Palackianae Olomucensis. Gymnica, 33(2), 7-11.

Kramer, H. C. (1980). Becoming a family therapist. New York, NY: Human Sciences Press.

Lazarus, R. S. (2006). Emotions and interpersonal relationships: Toward a person-centered conceptualization of emotions and coping. Journal of Personality, 74, 9-46. doi:10.1111/j.1467-6494.2005.00368.x

Lieberman, L. J. (1999). Physical fitness and adapted physical education for children who are deaf-blind. In L. Alsop (Ed.), Deaf-blind training manual (pp. 99-115). Logan, UT: SKI-HI Institute Press.

Lieberman, L. J., \& Stuart, M. E. (2002). Recreation preferences and barriers for adults with deaf-blindness. Journal of Visual Impairment and Blindness, 96, 724-735.

Lieberman, L. J., \& Taule, J. (1998). Including physical fitness into the lives of individuals who are deaf-blind. Deafblind Perspectives, 5(2), 6-10.

McInnes, J. (1999). A guide to planning and support for individuals who are deaf-blind. Toronto: University of Toronto Press.
Petroff, J. G. (1999). A national transition follow-up study of youth identified as deaf-blind "parents perspectives" (Unpublished doctoral dissertation). Temple University, College of Education, Philadephia, PA.

Plaňava, I. (2000). Manželství a rodiny. Struktura, dynamika, komunikace [Marriages and families: Structure, dynamics, communication]. Brno: Doplněk.

Priest, S. (1999). The semantics of adventure programming. In J. C. Miles \& S. Priest (Eds.), Adventure programming (pp. 111-114). State College, PA: Venture Publishing.

Ray, T. (1991). SCOLA leisure activity guide. St. Paul, MN: Minnesota's Governors Council on Disabilities \& ARCRamsey County.

Satirová, V. (1998). Kniha o rodině [Book about family]. Prague: Práh.

Scholl, K. G., McAvoy, L. H., Rynders, J. E., \& Smith, J. G. (2003). The influence of an inclusive outdoor recreation experience on families that have a child with a disability. Therapeutic Recreation Journal, 37, 38-57.

Seligman, M., \& Darling, R. B. (2007). Ordinary families, special children. New York, NY: The Guilford Press.

Simms, B. (2004). European guidelines on combating the social exclusion of deafblind people. UK: Sense International.

Smith, T. B. (1994). Guidelines: Practical tips for working and socializing with deaf-blind people. Burtonsville, MD: Sign Media Inc.

Sobotková, I. (2001). Psychologie rodiny [Psychology of family]. Prague: Portál.

Sobotková, I. (2003). Pěstounské rodiny [Foster families]. Prague: Czech Ministry of Labour and Social Affairs.

Spradley, J. (1980). Participant observation. New York, NY: Harcourt Brace Jovanovich.

Štěrbová, D. (2002). Rodinný stress a copingové chování v rodinách se sluchově postiženými dětmi [Family stress and coping behavior in families with children with hearing impairments] (Unpublished doctoral dissertation). Palacký University, Faculty of Arts, Olomouc.

Štěrbová, D. (2005). Rodina a dítě s hluchoslepotou - jak to co nejlépe zvládat? [Family and child with deaf-blindness - how to cope the best?]. In D. Štěrbová (Ed.), Hluchoslepota (pp. 9-12). Olomouc: Palacký University.

Štěrbová, D. (2013). Rodiny s postiženými dětmi. Tak „trochu jiné " rodiny? [Families with disabled children. Families of a different kind?]. Olomouc: Palacký University.

Thomas, J. R., \& Nelson, J. K. (1996). Research methods in physical activity (3rd ed.). Champaign, IL: Human Kinetics.

Vágnerová, M. (2009). Náročné mateřství. Být matkou postiženého ditěte [Challenging motherhood. Being a mother of a disabled child]. Prague: Karolinum.

Weiss, J. A. (2008). Role of Special Olympics for mothers of adult athletes with intellectual disability. American Journal of Mental Retardation, 113, 241-253. doi:10.1352/0895-8017 